MEXAHIKA

MECHANICS

https://doi.org/10.15407/dopovidi2021.05.033

УдК 539.3

В.Ф. Мейш, https://orcid.org/0000-0003-4141-7008

Ю.А. Мейш, https://orcid.org/0000-0001-7492-700X

Інститут механіки ім. С.П. Тимошенка НАН України, Київ

E-mail: vfmeish@gmail.com

\title{
Динамічна поведінка циліндричних оболонок некругового перерізу при нестаціонарних навантаженнях
}

Представлено академіком НАН Украйни О.М. Гузем

Розглядаються нестаціонарні хвильові прочеси в циліндричних оболонках некругового перерізу. Для опису хвильових процесів використовується модель теорії оболонок типу Тимошенка. Для отримання рівнянь коливань вихідної оболонки використовується варіаційний принцип Гамільтона - Остроградського. Рівняння коливань доповнюються відповідними природними граничними та нульовими початковими умовами. Чисельний розв’язок наведених в роботі задач базується на застосуванні інтегро-інтерполяційного методу побудови різницевих схем по просторових та часовій координатах. Як числовий приклад розглядалась задача динамічної поведінки циліндричної оболонки скінченої довжини еліптичного перерізу при дї розподіленого внутрішнього імпульсного навантаження. Наведено числові результати, які дозволяють проводити детальну характеристику напружено-деформованого стану вихідної циліндричної оболонки.

Ключові слова: ииліндрична оболонка, некруговий переріз, модель типу Тимошенка, нестачіонарні проиеси, чисельні методи

Циліндричні оболонки кругового й некругового поперечного перерізу широко застосовуються в різноманітних галузях техніки як конструктивні елементи машин і приладів. Напружено-деформований стан (НДС) циліндричної оболонки еліптичного перерізу при стаціонарних та нестаціонарних навантаженнях описується системою динамічних диференціальних рівнянь в частинних похідних зі змінними коефіцієнтами $[1-5,7]$. Тому розв'язання крайових задач для некругових оболонок пов’язане із деякими математичними труднощами. В основному розглядалися задачі на статичне деформування та стійкість оболонок.

На сьогоднішній день, в основному, отримано аналітичні та чисельні розв’язки динамічних задач визначення НДС оболонок канонічної форми (циліндричні, конічні, сферичні оболонки) [1, 6]. Аналітичні та чисельні розв’язки отримані в рамках класичної (модель Кірхгофа-Лява) та уточнюючої (модель Тимошенка) моделей оболонок [1, 6].

Ци т у в анн я: Мейш В.Ф., Мейш Ю.А. Динамічна поведінка циліндричних оболонок некругового перерізу при нестаціонарних навантаженнях. Допов. Нащ. акад. наук Укр. 2021. № 5. С. 33-38. https://doi.org/10.15407/dopovidi2021.05.033 
Нижче дано загальну постановку задач динаміки для циліндричних оболонок скінченої довжини некругового перерізу в рамках моделі оболонок типу Тимошенка і отримано чисельні розв’язки крайових задач для циліндричних оболонок еліптичного перерізу при динамічних навантаженнях.

Віднесемо циліндричну оболонку еліптичного перерізу до криволінійної ортогональної системи координат $\alpha_{1} \alpha_{2} z$. Координатні лінії $\alpha_{1}, \alpha_{2}$ належать серединній поверхні оболонки і збігаються з лініями головних кривизн; координатна лінія $z \in$ прямою, яка ортогональна до серединної поверхні. Будемо вважати величину $\mathfrak{s}$ додатною, якщо точка знаходиться зі сторони опуклості серединної поверхні.

Вирази для коефіцієнтів першої квадратичної форми і кривизн серединної поверхні циліндричної оболонки еліптичного перерізу мають вигляд [2, 3]

$$
\begin{aligned}
& A_{1}=1, \quad A_{2}=\left(a^{2} \cos ^{2} \alpha_{2}+b^{2} \sin ^{2} \alpha_{2}\right)^{1 / 2}, \\
& k_{1}=0, \quad k_{2}=a b\left(a^{2} \cos ^{2} \alpha_{2}+b^{2} \sin ^{2} \alpha_{2}\right)^{-3 / 2},
\end{aligned}
$$

де $a, b$ - пів осі еліпса.

При побудові математичної моделі динамічної поведінки циліндричної оболонки еліптичного перерізу будемо виходити з наступних припущень. Вважаємо, що напруженодеформований стан оболонки може бути визначений в рамках геометрично лінійного варіанта теорії оболонок типу Тимошенка [1].

Введемо позначення $s_{1}=\alpha_{1} A_{1}, s_{2}=\alpha_{2} A_{2}$, де $A_{1}, A_{2}$ - коефіцієнти першої квадратичної форми серединної поверхні циліндричної оболонки еліптичного перерізу.

Рівняння коливань для циліндричної оболонки еліптичного перерізу знаходимо використовуючи варіаційний принцип Гамільтона-Остроградського [1]

$$
\int_{t_{1}}^{t_{2}}[\delta(\Pi-K)+\delta A] d t=0,
$$

де $\Pi, K$ - потенціальна і кінетична енергії оболонки; А - робота зовнішніх сил.

Введемо позначення: $s_{1}=A_{1} d \alpha_{1}, s_{2}=A_{2} d \alpha_{2}$. Прирівнюючи до нуля вирази при незалежних варіаціях $\delta U_{1}, \delta U_{2}, \delta U_{3}, \delta \varphi_{1}, \delta \varphi_{2}$ у варіаційному функціоналі (2), отримаємо наступні рівняння коливань циліндричної оболонки еліптичного перерізу:

$$
\begin{aligned}
& \frac{1}{A_{2}} \frac{\partial}{\partial s_{1}}\left(A_{2} T_{11}\right)+\frac{1}{A_{1}} \frac{\partial}{\partial s_{2}}\left(A_{1} S\right)=\rho h \frac{\partial^{2} u_{1}}{\partial t^{2}}, \\
& \frac{1}{A_{2}} \frac{\partial}{\partial s_{1}}\left(A_{2} S\right)+\frac{1}{A_{1}} \frac{\partial}{\partial s_{2}}\left(A_{1} T_{22}\right)+k_{2} T_{23}=\rho h \frac{\partial^{2} u_{2}}{\partial t^{2}}, \\
& \frac{1}{A_{2}} \frac{\partial}{\partial s_{1}}\left(A_{2} T_{13}\right)+P_{3}+\frac{1}{A_{1}} \frac{\partial}{\partial s_{2}}\left(A_{1} T_{23}\right)-k_{2} T_{22}=\rho h \frac{\partial^{2} u_{3}}{\partial t^{2}},
\end{aligned}
$$




$$
\begin{aligned}
& \frac{1}{A_{2}} \frac{\partial}{\partial s_{1}}\left(A_{2} M_{11}\right)-T_{13}+\frac{1}{A_{1}} \frac{\partial}{\partial s_{2}}\left(A_{1} H\right)=\rho \frac{h^{3}}{12} \frac{\partial^{2} \varphi_{1}}{\partial t^{2}}, \\
& \frac{1}{A_{2}} \frac{\partial}{\partial s_{1}}\left(A_{2} H\right)+\frac{1}{A_{1}} \frac{\partial}{\partial s_{2}}\left(A_{1} M_{22}\right)-T_{23}=\rho \frac{h^{3}}{12} \frac{\partial^{2} \varphi_{2}}{\partial t^{2}} .
\end{aligned}
$$

Вирази для зусиль - моментів гладкої циліндричної оболонки приймаються згідно з [1]. Рівняння коливань доповнюються відповідними природними граничними та нульовими початковими умовами.

Чисельний алгоритм. Рівняння неосесиметричних коливань циліндричних оболонок еліптичного перерізу (3) являють собою систему диференціальних рівнянь в частинних похідних за змінними $s_{1}, s_{2}, t$. Різницевий алгоритм заснований на застосуванні інтегроінтерполяційного методу побудови скінчено-різницевих схем по просторових координатах і явній скінчено-різницевій апроксимації по часовій координаті [1, 6].

Перехід від неперервної системи (3) до скінчено-різницевої виконується в два етапи [1]: етап 1 полягає в скінчено-різницевій апроксимації рівнянь коливань (3) в зусилляхмоментах,

етап 2 полягає в скінчено-різницевій апроксимації зусиль-моментів і відповідних деформацій [1].

Виконуючи операцію інтегрування рівнянь (3) з використанням явної апроксимації по часовій координаті, отримаємо різницеві рівняння, які апроксимують вихідні рівняння (3) циліндричної оболонки еліптичного перерізу:

$$
\begin{aligned}
& \frac{1}{A_{2 l}}\left(\frac{\left(A_{2} T_{11}\right)_{l+1 / 2, m}^{n}-\left(A_{2} T_{11}\right)_{l-1 / 2, m}^{n}}{\Delta s_{1}}\right)+\frac{S_{l, m+1 / 2}^{n}-S_{l, m-1 / 2}^{n}}{\Delta s_{2}}=\rho h\left(u_{1 l, m}^{n}\right)_{\bar{t} t} ; \\
& \frac{1}{A_{2 l}}\left(\frac{\left(A_{2} S\right)_{l+1 / 2, m}^{n}-\left(A_{2} S\right)_{l-1 / 2, m}^{n}}{\Delta s_{1}}\right)+\frac{T_{22 l, m+1 / 2}^{n}-T_{22 l, m-1 / 2}^{n}}{\Delta s_{2}}+; \\
& +k_{2 l}\left(\frac{T_{23 l, m+1 / 2}^{n}+T_{23 l, m-1 / 2}^{n}}{2}\right)=\rho h\left(u_{2 l, m}^{n}\right)_{\overline{t t}} ; \\
& \frac{1}{A_{2 l}}\left(\frac{\left(A_{2} T_{13}\right)_{l+1 / 2, m}^{n}-\left(A_{2} T_{13}\right)_{l-1 / 2, m}^{n}}{\Delta s_{1}}\right)+\frac{T_{23 l, m+1 / 2}^{n}-T_{23 l, m-1 / 2}^{n}}{\Delta s_{2}}- \\
& -k_{2 l}\left(\frac{T_{22 l, m+1 / 2}^{n}+T_{22 l, m-1 / 2}^{n}}{2}\right)++P_{3}^{n}\left(S_{1 l}, S_{2 m}, t^{n}\right)=\rho h\left(u_{3 l, m}^{n}\right)_{\bar{t} t} \\
& \frac{1}{A_{2 l}}\left(\frac{\left(A_{2} M_{11}\right)_{l+1 / 2, m}^{n}-\left(A_{2} M_{11}\right)_{l-1 / 2, m}^{n}}{\Delta s_{1}}\right)+\frac{H_{l, m+1 / 2}^{n}-H_{l, m-1 / 2}^{n}}{\Delta s_{2}}-
\end{aligned}
$$




$$
\begin{aligned}
& -\frac{T_{13 l+1 / 2, m}^{n}+T_{13 l-1 / 2, m}^{n}}{2}=\rho \frac{h^{3}}{12}\left(\varphi_{1 l, m}^{n}\right)_{\bar{t} t} ; \\
& \frac{1}{A_{2 l}}\left(\frac{\left(A_{2} H\right)_{l+1 / 2, m}^{n}-\left(A_{2} H\right)_{l-1 / 2, m}^{n}}{\Delta s_{1}}\right)+\frac{M_{22 l, m+1 / 2}^{n}-M_{22 l, m-1 / 2}^{n}}{\Delta s_{2}}- \\
& -\frac{T_{23 l, m+1 / 2}^{n}+T_{23, m-1 / 2}^{n}}{2}=\rho \frac{h^{3}}{12}\left(\varphi_{2 l, m}^{n}\right)_{\overline{t t}} .
\end{aligned}
$$

В різницевих рівняннях (4) позначення різницевих функцій і різницевих похідних введені згідно з [1, 6].

Різницеві співвідношення, які пов’язують відповідні деформації з компонентами узагальненого вектора переміщень серединної поверхні гладкої циліндричної оболонки еліптичного перерізу приймаються згідно з [1].

Числові результати. Як числовий приклад розглядалась задача динамічної поведінки циліндричної оболонки скінченої довжини еліптичного перерізу при дії розподіленого внутрішнього імпульсного навантаження $P_{3}\left(s_{1}, s_{2}, t\right)$. Покладалось, що краї оболонки жорстко защемлені, тобто при $s_{1}=0$ та $s_{1}=L-u_{1}=u_{2}=u_{3}=\varphi_{1}=\varphi_{2}=\varphi_{3}=0$.

Початкові умови нульові. Розподілене імпульсне навантаження $P_{3}\left(s_{1}, s_{2}, t\right)$ задавалось наступним чином:

$$
P_{3}\left(s_{1}, s_{2}, t\right)=A \cdot \sin \frac{\pi t}{T}[\eta(t)-\eta(t-T)],
$$

де $A$ - амплітуда навантаження; $T$ - часовий інтервал навантаження. В розрахунках покладалось $A=10^{6}$ Па; $T=50 \cdot 10^{-6}$ с.

Розв'язувалася задача 3 наступними геометричними та фізико-механічними параметрами для оболонки: $E_{1}=E_{2}=7 \cdot 10^{10}$ Па; $v_{1}=v_{2}=0,3 ; h=10^{-2}$ м; $L=0,4$ м. Параметри

$U_{3} \cdot 10^{5}, \mathrm{M}$

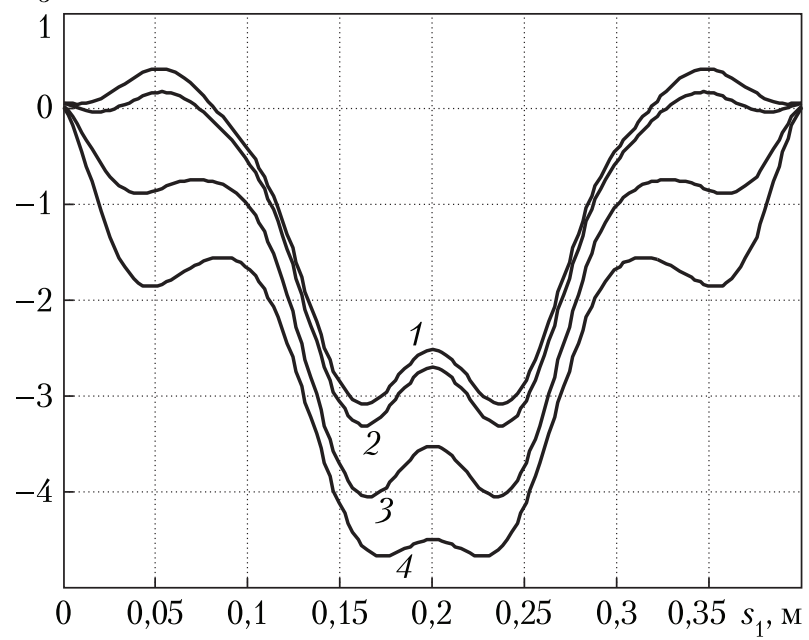

Puc. 1. еліптичного поперечного перерізу вибиралися такими: 1) $a / b=1 ; 2) a / b=1,01$; 3) $a / b=1,05$; 4) $a / b=1,1$ (далі криві на рисунку будуть позначатися відповідними індексами 1-4).

Розрахунки проведено для чотирьох вищевказаних варіантів еліптичного поперечного перетину циліндричної оболонки. Виконані вони в області $D=$ $=\left\{0 \leqslant s_{1} \leqslant L, 0 \leqslant s_{2} \leqslant A_{2} \pi / 2\right\}$. При розрахунках покладалася наступна кількість інтервалів по координатах $s_{1}$ та $s_{2}: N=160$, $M=60$.

Результати числових розрахунків для величин $u_{3}$ по довжині оболонки в переpiзi $s_{2}=0$ ілюструє рис. 1 , який відповідає 
залежності величини $u_{3}$ в перерізі $s_{2}=0$ вздовж координати $s_{1}-0 \leqslant s_{1} \leqslant L$ в момент часу $t=7 T$ (момент досягнення максимального за абсолютною величиною значення на розрахунковому інтервалі часу).

Висновки. В роботі дано постановку крайових задач для скінчених по довжині циліндричних оболонок еліптичного поперечного перерізу при дії динамічних навантажень. Система розв'язувальних рівнянь записана на основі співвідношень уточненої теорії непологих оболонок типу Тимошенка. Чисельний алгоритм будується на основі інтегро-інтерполяційного методу побудови різницевих схем по просторових та часовій координатах. Отримано чисельні розв’язки для замкнених циліндричних оболонок еліптичного поперечного перерізу, навантажених внутрішнім тиском.

\section{ЦИТОВАНА ЛІТЕРАТУРА}

1. Головко К.Г., Луговой П.З., Мейш В.Ф. Динамика неоднородных оболочек при нестационарных нагрузках. Киев. Изд. полиграф.центр “Киев. ун-т”, 2012. 541 с.

2. Григоренко Я.М., Захарийченко Л.И. Анализ напряженно-деформированного состояния некруговых цилиндрических оболочек при изменении их толщины и сохранении веса. Прикл. механика. 1999. 35, № 6. C. 39-47.

3. Григоренко Я.М., Будак В.Д., Григоренко О.Я. Розв'язання задач теорії оболонок на основі дискретноконтинуальних методів: навч. посібник. Миколаїв: Іліон, 2010. 294 с.

4. Мейш В.Ф., Мейш Ю.А., Бєлов Є.Д. Динаміка конічних оболонок еліптичного перерізу при нестаціонарних навантаженнях. Допов. Нащ. акад. наук Укр. 2018. № 1. С. 29-33. https://doi.org/10.15407/dopovidi2018.01.029

5. Новожилов В.В. Теория тонких оболочек. Ленинград: Судпромгиз, 1962. 432c.

6. Самарский А.А. Теория разностных схем. Москва: Наука, 1977. 656 с.

7. Meish V.F., MeishYu.A., Pavlyuk A.V. Dynamics of a Three - Layer Elliptic Cylindrical Shells Reinforced with Discrete Rings. Int. Appl. Mech. 2018. 54, № 2. P. 172-179.

https://link.springer.com/article/10.1007/s10778-018-0869-z

Надійшло до редакції 11.06.2021

\section{REFERENCES}

1. Golovko, K. G., Lugovoi, P. Z. \& Meish, V. F. (2012). Dynamics of inhomogeneous shells under nonstationary loads. Kyiv. Publ. Centre "KyivUniversity" (in Russian).

2. Grigorenko, Ya. M. \& Zakhariychenko, L. I. (1999). Analysis of the stress-strain state of non-circular cylindrical shells with a change in their thickness and conservation of weight, Prikl. Mechanics. 35, No. 6, pp. 39-47 (in Russian).

3. Grigorenko, Ya. M., Budak, V. D. \& Grigorenko, O. Ya. (2010). Determination of problems in the theory of shells on the basis of discrete-continuous methods. Mikolaiv: Ilyon (in Russian).

4. Meish, V. F., Meish, Yu. A. \& Bielov, Ye. D. (2018). Dynamics of end-shells of eliptic overrun in case of nonstationary replacement. Dopov. Nac. Acad. nauk Ukr. No. 1 (in Ukrainian). https://doi.org/10.15407/dopovidi2018.01.029

5. Novozhilov, V. V. (1962). Thinshelltheory. Leningrad: Sudpromgiz (in Russian).

6. Samarsky, A. A. (1977). The theory of difference schemes. Moscow: Nauka (in Russian).

7. Meish, V. F., Meish, Yu. A. \& Pavlyuk, A. V. (2018). Dynamics of a Three - Layer Elliptic Cylindrical Shells Reinforced with Discrete Rings. Int. Appl. Mech. 54, No.2, pp. 172-179.

https://link.springer.com/article/10.1007/s10778-018-0869-z

Received 11.06.2021 
V.F. Meish, https://orcid.org/0000-0003-4141-7008

Yu.A. Meish, https://orcid.org/0000-0001-7492-700X

S.P. Timoshenko Institute of Mechanics of the NAS of Ukraine, Kyiv

E-mail: vfmeish@gmail.com

\section{DYNAMIC BEHAVIOR OF CYLINDRICAL SHELLS}

OF NON-CIRCULAR CROSS-SECTION UNDER NON-STATIONARY LOADS

Non-stationary wave processes in cylindrical shells of non-circular cross-section are considered. A model of the Timoshenko-type shell theory is used to describe the wave process. The Hamilton - Ostrogradsky variational principle is used to derive the equations for the oscillations of the original shell. The oscillation equation is supplemented by the corresponding natural limiting and zero initial conditions. The numerical solution of the problems presented in the work is based on the use of an integro-interpolation method for constructing difference schemes in spatial and temporal coordinates. As a numerical example, the problem of the dynamic behavior of a cylindrical shell of a finite length of an elliptical section under the action of a distributed internal impulse load was considered. Numerical results are given, which make it possible to carry out a detailed characterization of the stress-strain state of the initial cylindrical shell.

Keywords: cylindrical shell, noncircular section, Timoshenko-type model, unsteady processes, numerical methods. 